\title{
The Quality of Farmland Protection in Canada: An Evaluation of the Strength of Provincial Legislative Frameworks
}

\author{
David J. Connell \\ University of Northern British Columbia
}

\begin{abstract}
Résumé
Les efforts continus des gouvernements pour protéger les terres agricoles ont abouti à un mélange d'intérêts, de politiques et de résultats. À travers ce document, nos objectifs sont d'évaluer les cadres législatifs provinciaux à travers le Canada et de mieux comprendre pourquoi certains cadres législatifs provinciaux pour protéger les terres agricoles sont meilleurs que d'autres. Dans notre étude, nous avons évalué et comparé la solidité de dix cadres législatifs provinciaux pour l'aménagement du territoire agricole. Nos résultats montrent que le Québec, la Colombie-Britannique et l'Ontario disposent des cadres législatifs les plus solides pour protéger les terres agricoles, tandis que les autres provinces canadiennes n'ont qu'une orientation politique modérée à faible. Cette situation laisse la plupart des terres agricoles du Canada très exposées à davantage de conversions et d'utilisations non agricoles. Les résultats illustrent également la façon dont les éléments clés d'un cadre législatif interagissent, servant soit à renforcer soit à nuire à la force globale de l'orientation des politiques, éclairant ainsi une approche stratégique de l'élaboration des politiques.
\end{abstract}

Mots-clés: protection des terres agricoles, aménagement du territoire agricole, évaluation de la qualité du plan, orientation politique

\section{Abstract}

Continuous efforts by governments to protect agricultural land has resulted in a mix of interests, policies, and outcomes. Through this paper, our aims are to evaluate provincial legislative frameworks across Canada and to improve our understanding of why some provincial legislative frameworks to protect agricultural land are better than others. In our study, we evaluated and compared the strength of ten provincial legislative frameworks for agricultural land use planning. Our results show that Québec, British Columbia, and Ontario have the strongest legislative frameworks to protect agricultural land, while the rest of Canada's provinces have only a moderate to weak policy focus. This situation leaves most of Canada's agricultural land highly exposed to more conversion and non-farm uses. The results also illustrate how key elements of a legislative framework interact, serving to either enhance or detract from overall strength of policy focus, thereby informing a strategic approach to policy development.

Keywords: farmland protection, agricultural land use planning, plan quality evaluation, policy focus

Canadian Planning and Policy/Aménagement et politique au Canada, Volume 2021, pages 109-130.

This work is licensed under a Creative Commons Attribution 4.0 International License.

ISSN 2562-122X

DOI 10.24908/cpp-apc.v2021i01.14229

CIP-ICU \& ACUPP-APUCU 


\section{INTRODUCTION}

In the 1960s and 1970s, the increased loss of farmland in peri-urban areas and the need to restrict urban sprawl heightened interests in protecting agricultural land. Over time, governments at all levels intervened to protect agricultural land through land use planning. In 1973, British Columbia (BC) was the first province to enact legislation to protect agricultural land (Smith, 2017; also Garrish, 2003; Rawson, 1976). The province of Québec adopted similar legislation in 1978 (Bryant et al., 2017; Glenn, 1983, 1985; Pierce \& Séguin, 1993). Ontario adopted land use guidelines for protecting agricultural lands in 1975 (Caldwell et al., 2017a). Gradually, other provinces intervened to protect farmland, as did regional governments (e.g., Lower Mainland Regional Planning Board, BC) and municipalities (e.g., Huron County, ON, and The Municipality of County of Kings, NS). The outcome is a mix of efforts by all levels of government (Caldwell et al., 2017b; Connell et al., 2019). Inevitably, compromises are made in pursuit of a desired balance of priorities among land uses while mitigating potential for conflicts among uses; some agricultural land is protected to some extent, with an acceptance that some agricultural land will be lost permanently. Consequently, areas across Canada have experienced significant losses of its agricultural land base, including the loss of some of Canada's best quality farmland to urban development (Hofmann, 2001; Hofmann et al., 2005; Statistics Canada, 2014, 2016). This combination of mixed responses from all levels of government and continued erosion of Canada's agricultural land base raises questions about the quality of land use policies and programs to protect farmland.

In this paper, we evaluate and compare the quality of provincial legislative frameworks in Canada. Our premise is that a higher quality (i.e., better) legislative framework is more likely to be implemented and produce desired outcomes (Brody et al., 2006). Drawing from the field of plan quality evaluation, we measure the strength of policy focus using a method developed by the author (Connell, 2020a, 2020b; Connell \& Daoust-Filiatrault, 2018). The coding protocol is based on four inter-related principles of policy focus: maximize stability; integrate public priorities across jurisdictions; minimize uncertainty; and accommodate flexibility. The scoring rubric is based on measures of each principle, which are then used to calculate an index of overall strength. Ratings of overall strength provide a means of comparison, with ordinal measures of strength for each principle forming the basis for explaining why one legislative framework is higher quality than another.

To date, most comparative studies have been based on programmatic summaries that highlight key similarities and differences. Among these, we review Alterman (1997) and Furuseth and Pierce (1982). We also review a recent report by the American Farmland Trust (AFT), Farms Under Threat: The State of States (AFT, 2020), which provides a comprehensive analysis of "policy response" by all 50 states to protect and preserve agricultural land. Building upon the methods of these studies, our approach adds an analytical framework that accounts for how key elements of a legislative framework interact to either enhance or detract from overall strength of policy focus. Thus, the aims of our research are to improve our understanding of differences among provincial legislative frameworks and our understanding of why one is better than another.

\section{COMPARATIVE STUDIES OF FARMLAND PROTECTION PROGRAMS AND POLICIES}

There is a variety of legislative frameworks that aim to protect agricultural land. These frameworks vary across countries (e.g., Alterman, 1997; Tan et al., 2009), states (AFT, 2020; Coughlin, 1991; Coughlin et al., 1980; Furuseth \& Pierce, 1982), and provincial jurisdictions (Connell et al., 2019), as well as local governments, which makes it challenging to do comparative studies. As Bryant and Russwurm (1982; also Nelson, 1990) explain, although many farmland protection policies and programs are similar, they may employ different tools and have different administrative structures that make it very difficult, and even impractical, to 
compare their schemes. On the other hand, Lowry (1980, p. 92) argues, "[a]lthough states vary widely with regard to what the state controls, it is possible to evaluate states in terms of how rigorously land use and environmental regulatory programs are enjoined." Notwithstanding inherent challenges, comparatives studies have considered both what governments control and how rigorously these controls are imposed. In turn, these studies have considered checklists of legislative elements and planning tools, identified general characterizations, and formulated typologies of approaches.

In most comparative studies, the results are largely restricted to general summaries of strengths and weaknesses, trends, and issues. Commonly, legislative frameworks are characterized as centralized, decentralized, or mixed (notably, Bryant \& Russwurm, 1982; also, for example, Glenn, 1983, 1985). Characterizations of government approaches are also based on the relative reliance on market forces versus regulation (e.g., Bray, 1980). Only a few studies that are based on programmatic summaries provide sufficient detail to suggest a method of systematic analysis. These studies include Alterman (1997) and Furuseth and Pierce (1982), for which we highlight the criteria and metrics used for each of their comparisons, as well as major insights.

Alterman (1997) compared institutional, policy, and contextual factors across six countries to determine "conditions for success or failure" (p. 220) of farmland protection policies. Using programmatic review and inductive analysis, Alterman identified the following conditions (and associated metrics) related to legislation: existence of direct farmland conversion controls (present/absent; weak/strong; stringent/flexible); type of planning system and levels of government (dominant/low role; hierarchical/integrated/decentralized; strong/weak guidance); local government incorporation and annexation powers (bottom-up/national; limited; strong); degree of overt redefinition of as countryside protection (low/high); commitment to urban containment and higher densities (metrics: low/high); compensation for development refusal (clear/unclear); degree of success in countryside preservation (low/high). Based on these conditions, Alterman found no clear association between success and some elements of the legislative frameworks, including degree of conversion control, type of planning system, and compensation rights. However, Alterman suggests that success can be related to five other factors: focus on "countryside preservation" or "farmland preservation"; national policy applied effectively by local planning authorities; containing urban growth; wide public support; and centralized power over incorporation and annexation. Overall, Alterman's approach informs criteria that can be used in future studies.

Furuseth and Pierce (1982) completed a comparative analysis of farmland protection programs in North America. They first compiled an inventory of protection mechanisms and of their prevalence in state and provincial governments. Based on inductive analysis, they then developed a typology of strategies based on a combination of five criteria and their respective metrics, as follows: discretion (non-voluntary/voluntary); focus (direct/indirect); organization (centralized/decentralized); linkage (integrated/non-integrated); and distribution (comprehensive/non-comprehensive). The typology of policy approaches is shown in Table 1 .

Table 1. Typology of farmland protection policy approaches

\begin{tabular}{|l|l|l|l|}
\hline Types of policy & Characteristics & Components & Evaluation \\
\hline $\begin{array}{l}\text { Comprehensive- } \\
\text { mandatory }\end{array}$ & $\begin{array}{l}\text { Non-voluntary, direct, } \\
\text { centralized, integrated, } \\
\text { comprehensive }\end{array}$ & $\begin{array}{l}\text { Differential tax } \\
\text { assessment, exclusive } \\
\text { agricultural zoning, } \\
\text { waiver of urban } \\
\text { assessments, land } \\
\text { banking }\end{array}$ & $\begin{array}{l}\text { Far exceeds other } \\
\text { policy types }\end{array}$ \\
\hline $\begin{array}{l}\text { Integrated- } \\
\text { voluntary }\end{array}$ & $\begin{array}{l}\text { Voluntary, direct, } \\
\text { decentralized, integrated, } \\
\text { non-comprehensive }\end{array}$ & $\begin{array}{l}\text { Differential tax } \\
\text { assessment, agricultural } \\
\text { districts, waiver of urban } \\
\text { assessments, transfer of } \\
\text { development rights, } \\
\text { executive power } \\
\text { discretion }\end{array}$ & $\begin{array}{l}\text { To a lesser degree, } \\
\text { far exceeds other } \\
\text { policy types; } \\
\text { politically more } \\
\text { feasible; may } \\
\text { represent the } \\
\text { politically ideal } \\
\text { policy }\end{array}$ \\
\hline $\begin{array}{l}\text { Indirect-police } \\
\text { power }\end{array}$ & $\begin{array}{l}\text { Non-voluntary, indirect, } \\
\text { decentralized, non- } \\
\text { integrated, } \\
\text { comprehensive }\end{array}$ & $\begin{array}{l}\text { Differential tax } \\
\text { assessment, centralized } \\
\text { land use controls } \\
\text { protection becomes } \\
\text { a secondary } \\
\text { concern; } \\
\text { centralized }\end{array}$ \\
\hline Indirect-financial & $\begin{array}{l}\text { Voluntary, indirect, } \\
\text { decentralized, non- } \\
\text { integrated, non- } \\
\text { comprehensive }\end{array}$ & $\begin{array}{l}\text { Differential tax } \\
\text { assessment, transfer of } \\
\text { development rights }\end{array}$ & $\begin{array}{l}\text { Tends to be weak } \\
\text { and haphazard; low } \\
\text { decision costs; } \\
\text { easiest type of } \\
\text { policy to enact }\end{array}$ \\
\hline
\end{tabular}


Importantly, as Furuseth and Pierce (1982, p. 196) note, while their inventory provides only a "checklist" of characteristics, their typology provides a "hierarchy of properties." As captured in the right-hand column in Table 1, the types of policies are listed in order from "far exceeds" to "weak and haphazard." They conclude that a multifaceted, comprehensive, mandatory approach far exceeds the other types.

In contrast to the inductive methods of the above studies, the AFT (2020) evaluated the ways that states have responded to threats to agricultural land. Using systematic analysis linked to normative criteria, AFT created the Agricultural Land Protection Scorecard (hereafter, ALP Scorecard). The ALP Scorecard is based on a state-by-state analysis of laws, regulations, and guidelines that govern six approaches: purchase of agricultural conservation easements (PACE) programs; land use planning policies; property tax relief; agricultural district programs; Farm Link (aka Land Link) programs; and state leasing programs. The AFT also reviewed websites and interviewed state agency staff. Of the six types of policy responses, we review only land use planning, which is most directly relevant to farmland protection.

To evaluate each state's policy score for land use planning, the AFT measured eight factors, with each factor assigned a weight of relative importance. The non-equal weighting rubric was informed by interviews with members of the project's advisory Committee. The factors, weights (points), and indicators are as follows:

- Authority (12.5 points): state authorization; state planning entity; state goal to protect agricultural land; and state goal to encourage compact growth.

- $\quad$ State Plan for Agriculture (12.5 points): efforts led by or involving state entities; clear goals to protect farmland; references to farmland protection and references to agricultural viability.

- $\quad$ Support for Comprehensive Planning (25 points): grants for comprehensive planning and provision of technical assistance for local planning.

- Comprehensive Planning Requirement (50 points for state requirements; 25 points if applicable to certain communities; 10 points for encouragements): tying ability to form planning bodies and/or ability to adopt zoning to plan development.

- Consistency with State Goals Requirement (50 points for consistency requirement; 25 points for states with incentives to encourage consistency).

- $\quad$ Requirement to Protect Agricultural Resources (50 points for mandate to protect; 12.5 points for requirement that communities merely address agricultural resources in local plans).

- Acres of Agricultural Land Developed per New Person: calculated acres developed per new person added to the state's population between 1982 and 2012; developed 50 brackets for the resulting values and assigned points.

The AFT highlights the following key outcomes of their analysis. Only twelve states have goals to protect agricultural land or manage growth. Only two states mandate local governments to protect agricultural and require consistency with state goals. For land use planning, the states with the highest scores are Oregon and Washington, followed by Maryland, Delaware, Rhode Island, Hawaii, California, Connecticut, Vermont, and Pennsylvania. The strongest approaches have goals to protect agricultural land and to promote compact growth; requirements to develop comprehensive plans; consistency between state goals and local plans; and requirements to adopt local policies to protect farmland.

Collectively, comparative studies demonstrate the value of examining the quality of farmland protection programs. Programmatic reviews help bring attention to legislative frameworks as objects of study and provide important insights to commonalities and differences of farmland protection programs. The studies completed by Alterman (1997) and Furuseth and Pierce (1982) 
identify possible criteria and associated metrics that can be applied across different programs. The AFT ALP Scorecard for land use planning provides ranked results using a scoring rubric based on weighted points for eight factors. As described next, the method we used aims to build upon these approaches by incorporating an explanatory framework.

\section{MethodS}

As Azarian (2011, p. 115) states, "comparing like and unlike phenomena is one of the most profound and generative perceptual processes on which much of our reasoning rests." The essence of methods of comparative analysis is to explicitly contrast cases in order to identify similarities and differences and the extent thereof along a certain dimension (e.g., more or less, better or worse). We use comparison to see things in perspective that we might take for granted otherwise and to explore, understand, and explain systematic differences among similar phenomena.

Our method of comparison draws from the field of plan quality evaluation, as described by Berke and Godschalk (2009) and Lyles and Stevens (2014). Within this field, our interest is to evaluate the strength of policy focus (Connell \& DaoustFiliatrault, 2018), which is distinguished from two other dimensions of plan quality: documentation (comprehensiveness) (e.g., Baer, 1997; Lyles \& Stevens, 2014) and communicative (persuasiveness) (e.g., Bunnell \& Jepson, 2011; Norton, 2008). Norton $(2005,2008)$ identified policy focus as an aspect of plan evaluation. Within the field of plan quality evaluation, quality is a measure of how good or bad something is. This measure derives from a process of evaluation using content analysis linked to normative criteria based on established standards of plan quality (Berke \& Godschalk, 2009; Lyles \& Stevens, 2014; Stevens, 2013). Thus, a plan, whether a single document or a set of legislative or public policy documents, is the object of evaluation.

The theoretical basis of the method to evaluate strength of policy focus draws from a sociological theory of planning (Connell, 2009). From this perspective, the function of planning is to help society deal with a future that cannot be fully known; planning makes a desirable future a visible part of today's decision making processes. Through planning processes and its outcomes (e.g., vision statements, statutory plans, and zoning bylaws) in conjunction with the legal system, planning maximizes what we can know about the future, thereby increasing a sense of stability, and minimizes what we do not know about the future, thereby decreasing uncertainty.

The method to evaluate strength of policy focus involves three components: identify relevant documents; coding; and scoring. The first step of the method is to identify elements that are relevant to agricultural land use planning, which can include legislation (e.g., laws, bylaws, and regulations), enforceable and aspirational policies, and governance structures (e.g., agricultural land commissions, planning advisory committees). Across Canada, relevant provincial elements include planning acts, local government (municipal) acts, statements of provincial interest (SPI), provincial land use policies (PLUP), and right to farm legislation, among others.

The remaining steps of the method are based on a coding protocol and scoring rubric. These techniques were developed initially as part of a national research program on agricultural land use planning in Canada. Since 2013, the author has completed evaluations of over 50 legislative frameworks of provincial, regional, and municipal governments. As the sets of data and results expanded, the coding protocol and scoring rubric were reviewed and refined continuously based on professional judgement of the researcher. For additional details about the development and application of the method, see Connell (2020a, 2020b).

\section{CODING PROTOCOL}

The next step of the method is to analyze the content of the documents, which is similar to interpreting legislative intent (Barker \& Anderson, 2019). The coding protocol is based on the 
following four principles, which are derived from the theoretical foundation of the method: maximize the stability of policy focus; integrate public priorities across jurisdictions; minimize uncertainty that undermines the policy intent; and accommodate flexibility without contributing unnecessarily to uncertainty (Connell, 2020a, 2020b; Connell \& Daoust-Filiatrault, 2018). We describe each of these four principles and relations among them, as follows.

The stability of a focus on protecting agricultural land is a combination of the type of document, terms used, and location within the document. Ideally, a stable legislative framework for protecting farmland is not easily changed, nor subject to the whim of shifting political interests. To maximize stability, a commitment should be expressed through clear, concise language that is entrenched through the best legislative means available (e.g., laws, regulations). Where a priority to protect agricultural land fits among other land use priorities should also be clear.

Integrating farmland protection as a public priority requires not only conformity across jurisdictions, integration also depends on whether planning approval of statutory plans and implementing bylaws is retained or delegated by a province. Through these means, integrating public priorities across jurisdictions is a foundation for building cohesion across upper- and lower-level governments. For provincial governments, there are two parts to the principle of integrating public priorities across jurisdictions. (1) Statutory requirements: what is the required level of integration (i.e., consistency) of lower-level policy with upper-level policy? (2) Statutory authority: what is the extent of the jurisdiction's authority over agricultural land use planning? The legal requirements for integration are usually in the form of an upper-level policy that requires a lower-level policy "to be consistent with" or "to conform to" upper-level policies, thus ensuring that lower-level policies are set within the context of broader public priorities.
The principle of minimizing uncertainty relates to how a government manages the threat of non-farm development to agricultural land; it concerns the management of non-agricultural lands. One way to minimize uncertainty is to ensure internal consistency, which exists when elements within a document align as well as when priorities and policies are consistent across documents that make up the legislative framework. For similar reasons, governments can also minimize uncertainty by eliminating loop-holes, ambiguous language, and open-ended conditions (e.g., "To protect farmland, whenever feasible"). Several planning tools also help to minimize uncertainty, including, and especially, designated urban growth boundaries. Recognizing "right to farm" legislation is also important because this policy supports the use rights of farmers to use their land and provides a legal argument for land use zoning and use of planning tools, such as covenants, thereby reducing the risk of conflicts that can arise from farm and non-farmuses of lands in close proximity.

The principle of accommodating flexibility concerns non-farm uses of agricultural lands and the interface between farm and non-farm uses. By accommodating flexibility, a government aims to address specific needs and interests without compromising the overall strength of the legislative framework to protect agricultural land. The challenge is to achieve a balance without being too stable so that a policy cannot be changed when needed or too strict so that it cannot be applied in a range of circumstances. Thus, some flexibility is needed to moderate the restrictive effects of maximizing stability and minimizing uncertainty, while also considering the negative impacts on the agricultural land base. Governance mechanisms, such as quasi-judicial provincial commissions, advisory committees, and application processes, serve as mechanisms to accommodate flexibility. Planning tools, such as agricultural impact assessments, and edge planning, should also be used to accommodate flexibility. Importantly, a government should address the other three principles before accommodating flexibility. 
Scoring rubric

For the scoring protocol, each of the four principles is scored for the presence and strength of specified items. A five-point scale from very weak (1) to very strong (5) is used, as described in Appendix A. Connell (2020a, 2020b) constructed the scale based on a review of the literature on farmland protection programs to identify elements that contribute to a successful program and on the set of elements used by all provinces in Canada.

The next step is to measure overall strength of policy focus. Following approaches used in plan quality evaluation (Lyles \& Stevens, 2014), the method calculates category scores and uses these scores to create an index of overall strength of policy focus. This index of overall quality enables us to rank plans on the premise that higher scores indicate a higher quality plan (Guyadeen, 2019; Horney et al., 2017; Stevens, 2013). Our measure of overall strength of policy focus is based on the sum of non-equal weighted scores for each principle, as presented in Appendix B, and summarized as follows. Given inter-relations among the principles, they are not independent.

- Stability is the cornerstone of the strength of policy focus. As such, it carries more weight than the other three principles. A score for maximizing stability is doubled.

- The weighting for integration across jurisdictions recognizes a relationship between integration and maximizing stability, whereby the significance of a requirement to integrate is greater when the senior government entrenches its commitment to protecting farmland in law. To account for this relationship, a higher weighting is given for integrating priorities with a higher score for maximizing stability.

- It is better for a government to make an effort to minimize uncertainty, and worse if it does not. Therefore, the weighting for minimizing uncertainty expands the 1-5 scale into a 0.5 7.5 scale.
A government should consider accommodating flexibility only after it addresses the other three principles. Correspondingly, the weighting is premised on the scores for the other three principles; a government is penalized for not taking care of the other three principles. The score for flexibility is adjusted down when the sum of scores for the three principles is lower.

After applying the weighting factors to each principle, all of the category scores are summed, with a maximum total score of 32.5. Categories of overall strength are based on a seven-point scale from very weak to very strong (Appendix B, Table e). However, there is room for interpretation when rating overall strength because the breakpoints between categories, e.g., between strong and very strong, are not intended to be precise. There is no meaningful difference between, for example, 18.49 and 18.5, yet these two overall scores lead to different overall ratings.

For our study, we evaluated all provinces in Canada, as follows (from west to east): British Columbia (BC), Alberta (AB), Saskatchewan (SK), Manitoba (MB), Ontario (ON), Québec (QC), New Brunswick (NB), Nova Scotia (NS), Prince Edward Island (PEI), and Newfoundland and Labrador (NL). For our purposes, we recognize substantive differences within the provinces of $\mathrm{BC}$ and Ontario, and treat each province as having two legislative frameworks. In $\mathrm{BC}$, one zone is covered by the ALC Act; the other zone is the northeast region of the province, which includes a substantial portion (about $31 \%$ ) of the province's agricultural lands. This northeast region has very high levels of oil and gas activities, which are governed by the Oil and Gas Commission (OGC). The ALC has a delegation agreement with the OGC, such that the OGC is responsible for carrying out the mandate of the ALC - while also being responsible for oil and gas development in agricultural areas. The delegation agreement views oil and gas developments as temporary uses of agricultural land and includes conditions for mitigating impacts of permitted activities. We denote these two zones as BC.ALC and BC.OGC. 


\section{Strength of provincial legislative frameworks to protect farmland}

(Note, these two zones are not related to the two ALR zones that existed from 2014 to 2019.) In Ontario, all agricultural land in the province is covered by the Provincial Policy Statement (PPS), with higher priorities for land designated as Prime agricultural land and Specialty Crop areas. In the Greater Golden Horseshoe area, which surrounds and includes the metropolitan area of the City of Toronto, a package of additional legislation applies, including the Greenbelt Act, Niagara Escarpment Planning and Development Act, and Places to Grow Act. We treat this "Greenbelt" area with an enhanced legislative framework as separate from the rest of the province. The effect of this additional legislation is to create two agricultural areas, one area of agricultural land covered by only the PPS (denoted as ON.PPS) and the agricultural land within the Greenbelt (denoted at ON.GB).

\section{Limitations}

Several limitations of the method must be noted. The evaluation of policy focus is a recent development in the field of plan evaluation, with farmland protection the first subject of its application. Thus, all aspects of the method and its application to agricultural land use planning will benefit from future research, with refinements improving the validity and reliability of the coding protocol and scoring rubric to measure strength, while also increasing its relevance for practising planners.

Presently, a critical limitation is a lack of consensus of what constitutes a "very strong" legislative framework to protect agricultural land. The metric we used is based on work completed within the Canadian context, although informed by international literature. The combined elements of the Québec and BC legislative frameworks are the primary sources of the standard for "very strong" while the diversity of elements employed among all provinces inform all elements of the scoring rubric.

Important limitations regarding the scoring rubric must also be noted. Although the premise of the rubric is to generate interval measures of strength for each of the four principles, it could be argued that the measures are only ordinal. The argument centres on the meaningfulness of the differences between data values. For ordinal measures, the difference between data values is either uneven or unknown; the quantitative difference between values is meaningless. Our method of content analysis aims for even measures of difference; however, at this stage, it is not possible to verify this, resulting, at best, in a weak interval measure. Thus, we acknowledge that our manipulation of the measures with mathematical operators can be viewed as problematic. With respect for these issues, we interpret our results only as if they are ordinal measures.

The present method does not include a prescribed checklist of items. Given the method's reliance on researcher interpretation for aspects of the method, from coding principles to interpreting measures of overall strength, the current coding protocol for policy focus evaluation is not amenable to tests of intercoder reliability, as prescribed by Stevens et al. (2014).

Differences across jurisdictions can present unique challenges for comparative studies (Azarian, 2011). Constitutional differences among nations, for example, can hinder or prevent direct comparison. For our study, this limitation concerns the extent to which the provincial legislative frameworks are directly comparable. Given that all of our cases are at the provincial level in Canada, asymmetrical comparison is not an issue, but this limitation would need to be addressed when comparing legislative frameworks across levels of jurisdiction and between nations.

\section{RESULTS}

The first results we present are summaries of scores for overall strength and each principle for all provinces. We then identify key legislation in each province that are most relevant to agricultural land use planning and reveal important differences among provinces. Third, we summarize key elements related to each of the four principles, and then provide a brief summary of each provincial legislative framework. 
For overall strength of policy focus, our results show that the provincial legislative frameworks to protect agricultural land range from strong to weak (Table 2). Québec has the strongest policy focus followed by BC (ALC) and Ontario (GB). The provinces of Nova Scotia, New Brunswick, Manitoba, and Saskatchewan have somewhat weak legislative frameworks. PEI, NL, and Alberta have weak frameworks (with the caveat that PEI recently amended its legislative framework and may yet adopt farmland protection policy). The results show a positive relation between overall strength and the rating for stability, which also reflects the greater weighting assigned for stability in the index. Another pattern evident in Table 2 is that all provinces (except BC.OGC) have at least a moderate rating for integration of priorities across jurisdictions, which enhances provincial commitments to protect agricultural land. While the weighting rubric accentuates differences at both ends of the scale, it also affects the middle of the scale, as evident with Nova Scotia. This provincial legislative framework has moderate ratings for all four principles, but its overall strength is somewhat weak.
Looking at the whole table, the diversity of all the results indicate that no two provinces have the same scores for all four principles.

The legal defensibility of a province's commitment to protect agricultural land underscores the strength of policy focus. Therefore, as part of the analysis, it is important to consider not only statements that pertain to protecting agricultural land but also the legal weight of the document in which the statement appears. As indicated in Table 3, the key legislative components employed by the provinces vary, including restrictive agricultural zones, quasi-judicial land commissions, PLUP, and SPI. Québec and BC are most similar, with other provinces incorporating either SPI or PLUP. The legislative form of SPI and PLUP also vary, including laws, regulations, enforceable policy, and aspirational policy. The stronger legislative frameworks rely more on laws and regulations, as also reflected in the scoring rubric. In the tables below, we use the following notation to identify elements of the legislative framework, as follows: legislation; regulations; enforceable policy; and aspirational policy.

Table 2. Provincial Legislative Frameworks: Assessment of Strength

\begin{tabular}{|l|c|c|c|c|c|}
\hline Province & Overall strength & Stability & Integration & Uncertainty & Flexibility \\
\hline QC & Strong & 5 & 4 & 4 & 3 \\
\hline BC.ALC & Somewhat Strong & 5 & 3 & 4 & 4 \\
\hline ON.GB & Somewhat Strong & 4 & 4 & 3 & 4 \\
\hline ON.PPS & Moderate & 3 & 4 & 3 & 4 \\
\hline BC.OGC & Moderate & 4 & 2 & 3 & 3 \\
\hline NS & Somewhat Weak & 3 & 3 & 2 & 2 \\
\hline NB & Somewhat Weak & 3 & 3 & 3 & 2 \\
\hline MB & Somewhat Weak & 3 & 4 & 2 & 2 \\
\hline SK & Somewhat Weak & 2 & 4 & 2 & 3 \\
\hline PE & Weak & 2 & 3 & 2 & 1 \\
\hline NL & Weak & 2 & 3 & 3 & 4 \\
\hline AB & Weak & 2 & 4 & 3 & 2 \\
\hline
\end{tabular}

$*=$ Very weak; $* * * * *$ Very strong 
Table 3. Provincial Legislative Frameworks: Key Components

\begin{tabular}{|c|c|c|c|c|}
\hline Province & $\begin{array}{l}\text { Province-wide } \\
\text { agricultural zone }\end{array}$ & $\begin{array}{l}\text { Agricultural land } \\
\text { commission }\end{array}$ & $\begin{array}{l}\text { Statement of } \\
\text { provincial interest } \\
\text { (or equivalent) }\end{array}$ & $\begin{array}{c}\text { Provincial } \\
\text { land use policy }\end{array}$ \\
\hline QC & $\checkmark$ & CPTAQ & LPTAA & Orientations \\
\hline BC & $\checkmark$ & ALC & $A L C A c t$ & \\
\hline ON & & & & $\underline{\text { PPS }}$ \\
\hline NS & & & $S P I$ & \\
\hline NB & & & & $\underline{\mathrm{ALP}}$ \\
\hline MN & & & & PLUP \\
\hline SK & & & SPI & \\
\hline \multicolumn{5}{|l|}{ PEI } \\
\hline NL & $\checkmark(\underline{\mathrm{ADA}})$ & & & \\
\hline $\mathbf{A B}$ & & & $A L S A$ & PLUP \\
\hline
\end{tabular}

ADA - Agricultural Development Area

ALC - Agricultural Land Commission

ALP - Agricultural Land Policy

LPTAA - Loi sur la protection du territoire et des activités agricoles

[ARPALAA - An Act Respecting the Preservation of Agricultural

Land and Agricultural Activities]

The four principles are central to evaluating the strength of policy focus. In particular, they are used to analyse the contents of documents that make up each legislative framework. In Table 4, we present a summary of the most direct and significant elements for each principle. The notation regarding legal defensibility is included in this table. The provinces are listed in order from highest to lowest overall strength of policy focus.

The diversity of all the results presented thus far indicates that each province has developed its own "formula" for achieving a desired level of farmland protection. Next, in order to highlight the main elements that define each approach and contribute to overall policy strength, we present the results by province, from strongest to weakest. Due to limits for the length of this paper, we focus on important aspects that contribute to overall strength identify.

\section{Québec}

The policy focus of Québec's legislative framework is strong overall, and the strongest among all CIP-ICU \& ACUPP-APUCU
PLUP - Provincial Land Use Policy PPS - Provincial Policy Statement SPI - Statement of Provincial Interest

provinces in Canada. Regarding stability, the most important element of Québec's legislative framework is the Loi sur la protection du territoire et des activités agricoles (LPTAA), which was enacted in 1978. The purpose of the LPTAA (c. P-41.1 c. 1 1.1) is to "secure a lasting territorial basis for the practice of agriculture, and to promote, in keeping with the concept of sustainable development, the preservation and development of agricultural activities and enterprises in the agricultural zones established by the regime." For this purpose, the LPTAA establishes a province-wide agricultural land reserve, a land use zone within which agriculture is a priority use, farming and ranching are encouraged, and non-farm uses are restricted. The LPTAA has priority over all other general or special laws.

Strong requirements for integrating public priorities for protecting agricultural lands in local land use plans are included in both the LPTAA (c. 3 s. 79.1) and Loi sur l'aménagement et l'urbanisme (LAU c. 1. s. 5). Both acts require local governments to promote agricultural purposes as the priority use of

118 Aménagement et politique au Canada 2021 


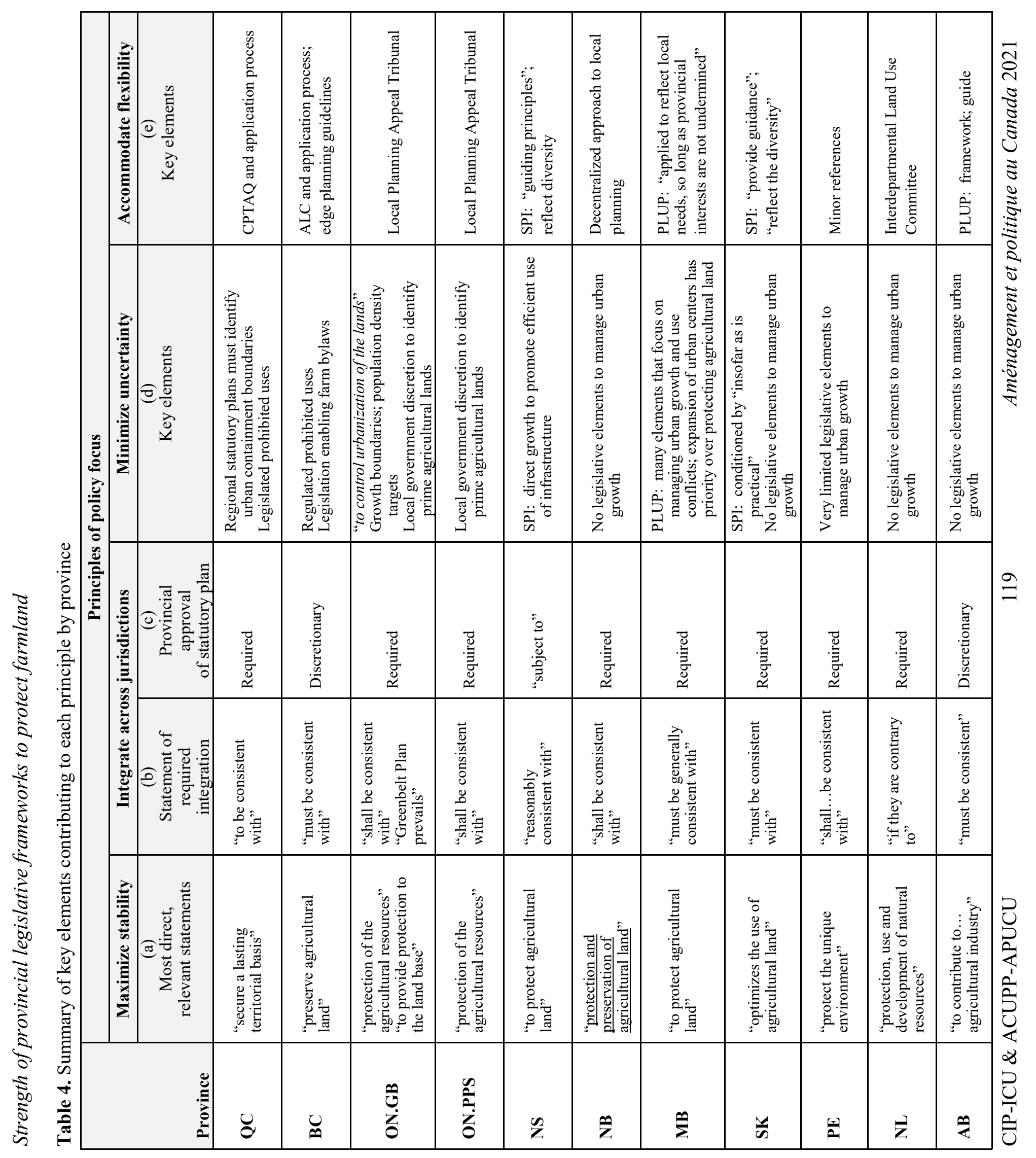


agricultural land. The LAU, which governs land use planning by local governments, includes the Orientations gouvernementales (or Guidelines). Land use plans of municipalities, metropolitan areas, and regional county municipalities (MRCs) must be consistent with the Guidelines.

The primary governance mechanism to accommodate flexibility is the Commission de protection $\mathrm{du}$ territoire agricole du Québec (CPTAQ), an autonomous, quasi-judicial body whose only function is to protect agricultural land. Central to the land management process are applications to CPTAQ, which cover including or excluding land from the agricultural land reserve, subdivision, and non-farm uses. A local government must fully substantiate an application to CPTAQ (LPTAA c.2 s.26). When rendering a decision (LPTAA c. 2 s. 62), CPTAQ must take a range of factors into consideration, including local conditions.

\section{British Columbia}

British Columbia and Québec are very similar, although $\mathrm{BC}$ has a lower rating of overall strength at somewhat strong. The primary element of the legislative framework is the Agricultural Land Commission Act (ALC Act), enacted in 1973 to establish the Agricultural Land Reserve (ALR) and the quasi-judicial Agricultural Land Commission (ALC). The ALC Act uses restrictive land zoning to protect agricultural land, plays a critical role in land use policies, and takes precedence over other legislation, including land use bylaws of local governments. The ALC Act and ALR contribute to a very strong level of stability. Strong language in the ALC Act and the Local Government Act (LGA) supports a strong level of integration between provincial interests in protecting farmland and local governments. However, the provincial government does not approve statutory plans. Instead, the LGA requires local governments only to consult with the ALC (s. 475(4)) and refer to the ALC for comment (s. 477(3)(b)), which undermine the strength of integration. Like the CPTAQ, the ALC is a quasijudicial tribunal with a mandate (s. 6) to protect the ALR.

\section{Ontario}

The policy focus of Ontario's legislative framework for the Greenbelt area (ON.GB) is somewhat strong overall. The strong stability of the legislative framework resides in the Planning Act, which sets goals for protecting farmland. The Provincial Policy Statement (PPS), which is an enforceable policy subject to review every five years, provides direction to local planning authorities for matters of provincial interest. All agricultural land in the province is covered by the PPS, with higher priorities for land designated as Prime agricultural land and Specialty Crop areas. Integration across jurisdictions is strong. Decisions of local planning authorities "shall be consistent with" the PPS and "shall conform with" provincial plans (Planning Act s. 3(5)). The identification of agricultural lands contributes to uncertainty. Local governments have the option to define "prime" agricultural lands, most often using a method that combines Canada Land Inventory (CLI) soil capability classifications with ratings of suitability (e.g., parcel size, nearby conflicting land uses). The standard method is Land Evaluation and Area Rating (LEAR).

\section{New Brunswick}

The overall strength of New Brunswick's framework is somewhat weak. The most important source of strength is the Agricultural Land Policy (ALP), adopted in 2017 "to provide a framework to guide government decision making relative to the protection and development of agricultural lands in the Province of New Brunswick" (p. 3). The ALP is an enforceable policy. The Agricultural Land Protection and Development Act (ALPDA) (s. 4(a)) establishes agricultural land owner associations, which have the legislated purpose "to promote and facilitate the stewardship, protection and improvement of agricultural land." A strength of the framework is strong integration of priorities across jurisdictions, primarily through ministerial approval of statutory plans. Importantly, the ALP states that land use planning in the province "shall reflect the importance of agriculture" (p. 6). The Community Planning Act (CPA) states that local government plans shall be consistent with provincial policy. 
However, the CPA has no specific references to the protection of agricultural land.

\section{Manitoba}

The policy focus of Manitoba's legislative framework is somewhat weak overall, with a moderate rating for stability. A provincial interest in protecting agricultural land is part of the PLUP, under the Provincial Planning Regulation (R.M. 81/2011). The PLUP (Policy Area 3) states, "Planning for the agricultural use of these lands and protecting them from conversion to non-farm use is vital to the future of Manitoba's agricultural sector." The legislative framework has a moderate level of integration. As required in The Planning Act (s.41), all local statutory land use plans must be submitted to the minister for approval. However, whereas most provinces use the term, "must be consistent with," The Planning Act uses the term "must be generally consistent." The Provincial Planning Regulation (Part 4) states that "generally consistent" means that statutory plans "will embody" and "reflect the spirit and intent" of the PLUP. To accommodate flexibility, the PLUP explains that the provincial interests, by their nature, are general and cannot account for all local situations, special circumstances, and exceptions; they are intended to accommodate local needs.

\section{Saskatchewan}

The policy focus of Saskatchewan's legislative framework is somewhat weak overall. The key elements of the provincial legislative framework are the Planning and Development Act (PDA) and the Statements of Provincial Interest Regulations (SPI). The rating for stability is weak because neither the PDA nor the SPI has a direct statement about farmland protection. The SPI states the province has an interest in supporting an agricultural sector that "optimizes the use of agricultural land for growth opportunities and diversification in primary agricultural production and value-added agribusiness" (Chapter P-13.2 Reg 3). The strong rating for integration reflects an emphasis on consistency between local land use planning with provincial interests, which is supported by the PDA and SPI. The Ministry reviews and approves all bylaws and subdivisions in rural municipalities.

\section{Nova Scotia}

The overall strength of Nova Scotia's legislative framework is somewhat weak. Although all principles rated as moderate, the weighting rubric lowers the overall rating. The most important contribution to stability is the SPI, which is part of the Municipal Government Act (MGA), and includes the following: "To protect agricultural land for the development of a viable and sustainable agriculture and food industry." To support integration, a rural municipality must address all of the SPI and give agricultural lands specific zoning with the intention to protect it. The MGA (s. 196) states, "Development undertaken by the Province and municipalities should be reasonably consistent with the statements." The Provincial Director of Planning must approve all statutory plans (MGA s. 208). Accommodating flexibility is an important factor when implementing the SPI. As the MGA (Schedule B, Introduction) states, the SPI statements "reflect the diversity found in the Province and do not take into account all local situations." As such, they are "general in nature" and provide guidance that "must be applied with common sense."

\section{Newfoundland and Labrador}

The overall strength of NL's legislative framework is weak. The primary elements of the provincial framework are the Urban and Rural Planning Act (URPA) and Lands Act. Notably, NL does not have a PLUP or SPI to protect farmland directly. Notwithstanding this weakness, several mechanisms contribute to stability. The Lands Act (s. 59) enables the creation of Agricultural Development Areas (ADAs), which are protected agricultural zones to control development and topsoil removal. However, only two zone have been established. The Forestry and Agrifoods Agency has a mandate to oversee all matters relating to, among other things, the use, protection, and development of agricultural land. The Agency's Land Use Program includes purchasing agricultural land in ADAs to protect the agricultural land base and provide land to farmers. Regarding 
integration, the URPA (s. 15) requires statutory plans to be reviewed by the province.

\section{Prince Edward Island}

The overall strength of PEI's legislative framework is weak. The primary elements of the provincial legislative framework are the Planning Act and Subdivision and Development Regulations. Due to the relatively small size of the province, the function of land use planning is more like of that a local government than other provinces. Notably, only 11 percent of PEI's land base is covered by municipal statutory plans and zoning bylaws. In 2017, new legislation for land use planning was enacted and, as of 2022, all municipalities will be required to develop statutory plans and zoning bylaws. Some of the approved amendments are not yet in force, including provisions that focus on the importance of protecting natural resources, including agricultural land. There are no statements in the legislative framework that provide a direct, clear commitment to protect agricultural land. The Subdivision and Development Regulation includes Special Planning Areas (SPAs) for which one of the objectives for development is to "minimize the loss of primary industry lands" (3 (b)).

\section{Alberta}

Overall, Alberta's legislative framework for protecting farmland is weak. The primary elements are the Alberta Land Stewardship Act (ALSA),Municipal Government Act (MGA), and provincial Land Use Policies (PLUP). The PLUP is an enforceable policy. The framework is designed to assert provincial land use priorities while respecting the land use authority of local governments; however, it does so without a clear commitment to protecting agricultural land. Regional plans developed under ALSA are the most important mechanisms for asserting provincial interests because the plans are approved by the provincial Cabinet, treated as provincial regulations, and take precedence over the PLUP priorities. However, only two of seven plans have been completed. Regarding agricultural land under PLUP, the stated goal is to "contribute to the maintenance and diversification of
Alberta's agricultural industry" (s. 6.1). Municipalities are encouraged to identify land for primary agricultural use and to limit fragmentation and premature conversion. Under ALSA, the strongest statements aim to support the agricultural industry and operations, rather than the land base. The MGA (Pt. 17 s. 622(3)) states that every statutory plan and land use bylaw "must be consistent with the [provincial] land use policies."

\section{Discussion}

In its simplest form, our approach looks at the quality of a legislative framework to understand how good it is. Our measure of quality is the strength of policy focus. An advantage of this approach is the ability to compare legislative frameworks directly, which means we can rank legislative frameworks from better to worse, from stronger to weaker. Thus, based on our analysis, we can state that the provinces of Québec, BC (ALC), and Ontario (GB) have the strongest provincial legislative frameworks in Canada. These results are consistent with previous research. Although past studies have not compared overall strengths of provincial legislative frameworks, Québec, $\mathrm{BC}$, and Ontario are considered among the most comprehensive provincial legislative frameworks (e.g., Bray, 1980; Bryant \& Russwurm, 1982; Caldwell et al., 2017b; Glenn, 1985). Pierce and Séguin (1993), for example, characterize BC and Québec as having the most protected approaches. Although our work does not measure the degree of centralization explicitly, our examination of integration across jurisdictions supports previous analyses. For example, Bryant and Russwurm (1982) describe a mixed use of centralized and decentralized government approvals; Glenn (1985) highlights the more direct, centralized approach of Québec compared to the less direct, more decentralized approach of Ontario.

Critically, our results highlight that many provinces have chosen not to protect its agricultural land base to the extent possible through legislative mechanisms. Most of Canada's provinces have only moderate to weak legislative frameworks, which means that only $7 \%$ of Canada's best (i.e., prime or 
highest capability) agricultural land is protected by provincial legislative frameworks that are at least somewhat strong, as highlighted in Table 5. Prime agricultural land (also referred to as "dependable") is defined as land with CLI soil capability Classes from 1 to 3, inclusively. For reference, CLI Classes 1 to 4 are often referred to as "productive" agricultural land.

Table 5. Overall strength of policy focus by jurisdiction in relation to proportion of total prime agricultural land in Canada

\begin{tabular}{|c|c|c|c|}
\hline Province & Overall strength & $\begin{array}{c}\% \text { of total } \\
\text { prime land in } \\
\text { Canada* }\end{array}$ & $\begin{array}{l}\text { Cumulative \% } \\
\text { of total prime } \\
\text { land in Canada }\end{array}$ \\
\hline $\mathrm{QC}$ & Strong & 5.0 & 5.0 \\
\hline BC.ALC & Somewhat strong & 0.8 & 5.8 \\
\hline ON.GB & Somewhat strong & 1.2 & 7.0 \\
\hline ON.PPS & Moderate & 14.4 & 21.4 \\
\hline BC.OGC & Moderate & 0.6 & 22.0 \\
\hline NS & Somewhat weak & 2.4 & 24.4 \\
\hline NB & Somewhat weak & 3.2 & 27.6 \\
\hline $\mathrm{MB}$ & Somewhat weak & 11.4 & 39.0 \\
\hline SK & Somewhat weak & 38.6 & 77.6 \\
\hline PEI & Weak & 0.8 & 78.4 \\
\hline NL & Weak & 0.01 & 78.4 \\
\hline $\mathrm{AB}$ & Weak & 21.6 & 100 \\
\hline
\end{tabular}

Note: Prime includes CLI Classes 1 to 3.

* Source: Hofmann, Filoso, and Schofield (2005)

Even for provinces that have strong legislative elements that contribute to stability, commitments to protect agricultural land are undermined by not integrating public priorities with lower jurisdictions or by failing to minimize uncertainty. This is to say that simply promoting a strong commitment to protecting farmland is not enough; rather, a strong commitment must be formulated in relation to all four principles. For example, multiple elements of the legislative frameworks in Québec and $\mathrm{BC}$ contribute to very strong ratings for stability. All of Nova Scotia, New Brunswick, Manitoba, and Saskatchewan have a PLUP or SPI that expresses a commitment to protecting agricultural land but none has restrictive zoning for agricultural land. The main reason for a weak legislative framework in PEI, NL, and Alberta is the absence of a statement of provincial interest or land use policy for protecting agricultural land. To gain insight to how key elements contribute to or detract from overall strength of each provincial legislative framework, we will discuss the results of our analysis in relation to each of the four principles.

\section{Maximize stability}

Key statements related to stability represent the most important, concise, and direct declarations of each province's commitment to protecting agricultural land. Given the importance of these statements in context of the legislative framework as a whole, all scores are doubled, which also accentuates differences. The ratings for stability range from very strong to weak (Table 2). All of the provinces, except Alberta, express a commitment to protecting agricultural land; Alberta refers to support for the agricultural industry. For most provinces, their commitments are to protect or preserve agricultural land, although there are slight differences in the wording. Most of these statements appear in provincial laws, which contribute most to stability.

Different ratings among provinces relate to the extent to which the key statements are supported by additional legislative elements. In this regard, Québec and BC stand out for making not only a commitment to protecting agricultural land but also by making agricultural use as a priority and establishing restrictive zones within which agriculture is a priority use, farming and ranching are encouraged, and non-farm uses are restricted. In both provinces, the laws protecting agricultural land prevail over other provincial and local laws. Both provinces also have quasi-judicial commissions with legislated mandates to protect agricultural land. In the Greenbelt area of Southern Ontario, prime agricultural land and specialty crop areas have a similar level of protection. The province of Newfoundland and Labrador have laws enabling the creation of restrictive agricultural zones; however, only two ADAs have been established. In contrast, other provinces include a commitment to protecting agricultural land as one of several land uses that are of provincial interest. 


\section{Integrate priorities across jurisdictions}

As shown in Table 4, two important aspects of integration are statement of required integration (column b) and provincial approval of statutory plan (column c). There is consistency among the legislated requirements for integrating provincial interests with local government planning and development, with some differences standing out. Whereas most provinces require local governments "to be consistent with," Manitoba and Nova Scotia include qualifiers, respectively, "generally consistent" and "reasonably consistent." In Manitoba, the Provincial Planning Regulation (Part 4) states that "generally consistent" means that statutory plans "will embody" and "reflect the spirit and intent" of the PLUP. Most provincial governments require that local government planning documents be approved by the province; provincial review is discretionary in $\mathrm{BC}$ and Alberta.

For all provinces, the ratings for required integration (Table 2, above) are moderate or stronger. Further, the weighting rubric ties integration with stability, whereby a combination of stronger stability and stronger integration are very important. This weighting, in addition to the doubling of stability scores, has a cumulative effect of valuing a strong commitment to protect agricultural land. In this regard, the scoring rubric accentuates this important difference between Québec from BC regarding integration, which are very similar otherwise.

\section{Minimize uncertainty}

Aspects of a legislative framework can help to minimize uncertainty while other aspects contribute to uncertainty, which encompass both positive and negative elements. For all provinces, the ratings range from very weak (New Brunswick) to strong (Québec and BC). One positive aspect of minimizing uncertainty relates to how a government manages the threat of non-farm development to agricultural land. In this regard, our attention shifts to non-agricultural lands and, in particular, to the extent to which a legislative framework addresses urban growth, as highlighted in Table 4, column (d). Québec requires regional governments to designate urban growth boundaries, which its member municipalities must recognize. Ontario's Greenbelt area stands out for its effort to manage growth, which includes urban growth boundaries, population density targets, and intensification objectives. At the same time, this very positive contribution to minimizing uncertainty is offset by the discretion afforded to local governments to define "prime" agricultural land within their jurisdictions, thus exposing agricultural land to an uncertain future through periodic review as conditions change. Several province's have no legislative elements that address urban growth and development, thus exposing agricultural lands to non-farm development.

\section{Accommodate flexibility}

Flexibility is about accommodating non-farm uses and development within agricultural areas, without contributing to uncertainty, while also mitigating impacts on agricultural activities. The ratings range from strong ( $\mathrm{BC}$ and Ontario) to very weak (Alberta). In BC and Québec, the agricultural land base is managed through a formal applications to the agricultural land commissions. These applications cover including or excluding land from the agricultural land reserve, subdivision, and non-farm uses. An applicant must fully substantiate their request and, when rendering a decision, the commission must consider a range of factors, including agricultural capability of the land, suitability of the proposed use, impact on the agricultural industry in the area, and, to some extent, local socio-economic conditions.

The use of SPI or PLUP are usually premised on flexibility. The documents are intended as guides or frameworks for local land use decisions, recognize the diversity of the provincial landscape and economic interests, and emphasize the need to consider all of the stated provincial interests as a whole, with no implied priority for any one. As stated in Alberta's land use policy, the document is not intended to be the basis for legal arguments.

Importantly, the influence of elements of flexibility in a legislative framework depend on how well agricultural land is protected overall, as reflected in 
the weighting scheme that is based on the combined scores of the other three principles. Newfoundland and Labrador and Ontario (PPS) have stronger scores for flexibility than they do for stability, which serves to undermine the provincial commitment to protect agricultural land.

Comparing provinces by each principle is particularly valuable when we note that no legislative framework among the provinces is the same. Although each province has its own formula for achieving a desired level of farmland protection, the results also illustrate that there are multiple ways to achieve a similar level of strength. For example, $\mathrm{BC}$ and Ontario (GB) are both somewhat strong; Nova Scotia, New Brunswick, Manitoba, and Saskatchewan are all somewhat weak. Having multiple paths to the same outcome means that governments have a choice beyond a checklist of items, and can ask, "How can we leverage the legislative elements available to us in order to increase overall strength?" The results of our study provides some examples.

For example, we can consider how the legislative frameworks for $\mathrm{BC}$ and Ontario might be strengthened. In $\mathrm{BC}$, a significant weak element of the framework is the absence of required provincial approval for local government planning documents. This factor is important not only for integrating a commitment to protect farmland across jurisdictions, it also enhances the value of a strong commitment, which $\mathrm{BC}$ has. By requiring provincial approval, the rating for integration would increase to strong, and the rating for overall strength would also increase to strong, the same rating as Québec. In Ontario, the Greenbelt Plan (which consists of several legislative elements) is highly regarded as a planning strategy, including its protection of agricultural land (Caldwell et al., 2017a). As already noted, we consider the discretion given to local governments a significant weakness of the legislative framework. If prime agricultural lands were designated by the province then this change would improve the rating for uncertainty to strong, with a corresponding change in overall strength from somewhat strong to strong. At the same time, we believe that tools like LEAR (Land Evaluation and Area Rating), which is used in Ontario to define prime agricultural lands, can be used very effectively to accommodate flexibilitywithin the context of the whole legislative framework.

As illustrated, addressing major weak elements could help significantly to improve overall strength. However, we also know that a commitment to protect agricultural land can be undermined by lesser known or over-looked weak elements. People who want to convert or alienate agricultural land can and will do their best to find a way through the legislative framework to serve their interests. This strategy is employed not only by land owners but also by governments. The use of Ministerial Zoning Orders (MZOs) by the Province of Ontario provides a current example. Although intended for exceptional circumstances, MZOs are being used presently to advance non-farm development on agricultural lands and natural habitats (Ontario Farmland Trust (2021) and, broadly, to undermine the statutory planning system (Federation of North Toronto Residents' Associations, 2020; Ontario Nature, 2021). Recent (Schedule 17 of Bill 197) and proposed changes (Schedule 3 of Bill 257) to the legislative framework will contribute to uncertainty and reduce the overall strength of Ontario's provincial legislative framework to protect agricultural land.

Analyzing the strength of a legislative framework using the four principles of the method used in this paper illustrates the value of paying attention to not only provincial statements of interest to protect farmland (maximize stability), but also to the other three principles that guide policy development. Sometimes the weaker elements can be the most problematic.

This way of understanding the strength of a provincial legislative framework also lends insight to the prospects of an ideal framework to protect agricultural land. The methods and results of our analysis point to an ideal provincial legislative framework. The top row of Table 5, presents the criteria for each principle that contribute to a very 
strong framework. We can then look to the strengths of each province for examples of how these principles are operationalized. However, given the potential for a strong legislative framework to be circumvented by weak elements, it can be argued that the only ideal policy is a moratorium on the conversion and alienation of agricultural land.

\section{CONCLusion}

In our study, we examined the quality of farmland protection policy by evaluating and comparing the strength of ten provincial-level legislative frameworks for agricultural land use planning. The results reveal a range of strengths from strong to weak across frameworks that employ different approaches, including agricultural zones with restricted non-farm uses, quasi-judicial tribunals, statements of provincial interest (SPI), and provincial land use policies (PLUP). Québec, BC, and Ontario have the strongest frameworks, yet these provinces encompass a small percentage of prime agricultural land. Critically, only $7 \%$ of Canada's highest-capability agricultural land is protected by at least somewhat strong frameworks, leaving the vast majority highly exposed to nonfarm uses.

For planners and policymakers, the results also reveal that provincial governments can be strategic about their approach, as there are different ways to achieve a desired strength of policy focus. A very strong policy focus, however, must draw upon a full complement of strengths. To For this purpose, the four principles employed for this analysis offer a framework that can guide policy development.

\section{ACKNOWLEDGMENTS AND GRANTS}

This research initiative was supported by the Social Science and Humanities Research Council of Canada (435-2013-1726). The researcher has no actual or potential conflicts of interest with respect to remuneration for conducting or being involved with any part of the study

\section{CORRESPONDING AUTHOR}

Dr. David Connell, RPP MCIP, is an Associate Professor in Ecosystem Science and Management at the University of Northern British Columbia. Their research centres on agricultural land use planning to protect farmland (www.aglup.org), with publications in the areas of plan evaluation (plan quality), planning theory, and farmland protection.

David J. Connell

Associate Professor

University of Northern British Columbia

3333 University Way, Prince George,

Canada, V2N 4Z9

Tel: 250-960-5835

Email: david.connell@unbca.ca

\section{REFERENCES}

Alterman, R. (1997). The Challenge of Farmland Preservation: Lessons from a Six-Nation Comparison. Journal of the American Planning Association, 63(2), 220-243. https:// doi.org/10.1080/01944369708975916

American Farmland Trust [AFT]. (2020). Farms under threat: The state of the states. Washington, DC: American Farmland Trust.

Azarian, R. (2011). Potentials and Limitations of Comparative Method in Social Science. Journal of Humanities and Social Science, 1, 113-125.

Baer, W. C. (1997). General Plan Evaluation Criteria: An Approach to Making Better Plans. Journal of the American Planning Association, 63(3), 329-344. https:// doi.org/10.1080/01944369708975926

Barker, S., \& Anderson, E. (2019). Researching legislative intent: A practical guide. Toronto, ON: Irwin Law Inc.

Berke, P., \& Godschalk, D. (2009). Searching for the Good Plan: A Meta-Analysis of Plan Quality Studies. Journal of Planning Literature, 23(3), 227-240. https:// doi.org/10.1177/0885412208327014

Bray, C. E. (1980). Agricultural Land Regulation in Several Canadian Provinces. Canadian Public Policy / Analyse de Politiques, 6(4), 591-604. https://doi.org/10.2307/3549758

Brody, S. D., Carrasco, V., \& Highfield, W. E. (2006). Measuring the Adoption of Local Sprawl: Reduction Planning Policies in Florida. Journal of Planning Education and Research, 25(3), 294-310. https:// 


\section{Strength of provincial legislative frameworks to protect farmland}

\section{doi.org/10.1177/0739456X05280546}

Bryant, C. R., Marois, C., Granjon, D., \& Chahine, G. (2017). Agricultural land protection in Québec. In W. J. Caldwell, S. Hilts, \& B. Wilton (Eds.), Farmland Preservation Land for Future Generations (pp. 28-45). Winnipeg, MB: University of Manitoba Press.

Bryant, C. R., \& Russwurm, L. H. (1982). North American farmland protection strategies in retrospect. GeoJournal, 6(6), 501-511. https://doi.org/10.1007/BF00425313

Bunnell, G., \& Jepson, E. J. (2011). The Effect of Mandated Planning on Plan Quality: A Fresh Look at What Makes "A Good Plan.” Journal of the American Planning Association, 77(4), 338-353. https://

doi.org/10.1080/01944363.2011.619951

Caldwell, W., Hilts, S., \& Wilton, B. (2017). Farmland preservation in Ontario. In W. J. Caldwell, S. Hilts, \& B. Wilton (Eds.), Farmland Preservation Land for Future Generations (pp. 46-63). Winnipeg, MB: University of Manitoba Press.

Caldwell, W. J., Hilts, S., \& Wilton, B. (2017). Farmland preservation in Ontario. Winnipeg, MB: University of Manitoba Press.

Connell, D. J. (2009). Planning and its Orientation to the Future. International Planning Studies, 14(1), 85-98. https:// doi.org/10.1080/13563470902741609

Connell, D. J. (2020a). Evaluating the Strength of Local Legislative Frameworks to Protect Farmland: City of Richmond and Metro Vancouver, British Columbia. Journal of Planning Education and Research, 0739456X2094393. https://doi.org/10.1177/0739456X20943930

Connell, D. J. (2020b). Protecting farmland: Principles and beneficial practices. Plan Canada, 60(1), 8-12.

Connell, D. J., Bryant, C. R., Caldwell, W. J., Cameron, G., \& Johnston, T. (2019). Protecting farmland in Canada: Provincial legislative frameworks. In H. McLeod-Kilmurray, A. Lee, \& N. Chaliflour (Eds.), Food law and policy in Canada (pp. 113-173). Toronto, ON: Carswell.

Connell, D. J., \& Daoust-Filiatrault, L.-A. (2017). Better Than Good: Three Dimensions of Plan Quality. Journal of Planning Education and Research, 0739456X1770950. https://doi.org/10.1177/0739456X17709501

Coughlin, R. E. (1991). Formulating and Evaluating Agricultural Zoning Programs. Journal of the American Planning Association, 57(2), 183-192. https:// doi.org/10.1080/01944369108975486

Coughlin, R. E., Keene, J. C., Esseks, J. D.,Toner, W., \& Rosenberger, L. (1980). The protection of farmland: a reference guidebook for state and local governments. Washington, DC: National Agricultural Lands Study.
Federation of North Toronto Residents' Associations. (2020, October 17). Minister's Zoning Orders.

Furuseth, O. J., \& Pierce, J. T. (1982). A Comparative Analysis of Farmland Preservation Programmes in North America. The Canadian Geographer / Le Géographe Canadien, 26(3), 191206. https://doi.org/10.1111/j.1541-0064.1982.tb01448.x

Garrish, C. (2002). Unscrambling the Omelette: Understanding British Columbia's Agricultural Land Reserve. BC Studies: The British Columbian Quarterly, (136), 25-55. https:// doi.org/10.14288/bcs.v0i136.1649

Glenn, J. M. (1983). L'intervention de I'état dans I'agriculture: Un aperçu 1égislatif. McGill Law Journal, 28(4), 928-976.

Glenn, J. M. (1985). Approaches to the Protection of Agricultural Land in Quebec and Ontario: Highways and Byways. Canadian Public Policy / Analyse de Politiques, 11(4), 665676. https://doi.org/10.2307/3550297

Guyadeen, D. (2019). Evaluating the Quality of Municipal Official Plans in the Ontario-Greater Golden Horseshoe Region, Canada. Journal of Planning Education and Research, 0739456X1985964. https:// doi.org/10.1177/0739456X19859648

Hofmann, N. (2001). Urban consumption of agricultural land. Rural and small town Canada analysis bulletin 3(2). Ottawa: Statistics Canada, Catalogue no. 21-006-XIE.

Hofmann, N., Filoso, G., \& Schofield, M. (2005). Rural and small town Canada analysis bulletin, 6(1). Ottawa: Statistics Canada, Catalogue no. 21-006-XIE.

Horney, J., Nguyen, M., Salvesen, D., Dwyer, C., Cooper, J., \& Berke, P. (2017). Assessing the Quality of Rural Hazard Mitigation Plans in the Southeastern United States. Journal of Planning Education and Research, 37(1), 56-65. https:// doi.org/10.1177/0739456X16628605

Lowry, G. K. Jr. (1980). Evaluating State Land Use Control: Perspectives and Hawaii Case Study. Urban Law Annual, 18, 85-128.

Lyles, W., \& Stevens, M. (2014). Plan Quality Evaluation 19942012: Growth and Contributions, Limitations, and New Directions. Journal of Planning Education and Research, 34 (4), 433-450. https://doi.org/10.1177/0739456X14549752

Nelson, A. C. (1990). Economic critique of U.S. prime farmland preservation policies: Towards state policies that influence productive, consumptive, and speculative value components of the farmland market to prevent urban sprawl and foster agricultural production in the United States. Journal of Rural Studies, 6(2), 119-142. https://doi.org/10.1016/0743-0167 (90)90001-O

Norton, R. K. (2005). More and Better Local Planning: StateMandated Local Planning in Coastal North Carolina. Journal of the American Planning Association, 71(1), 55-71. https:// $\underline{\text { doi.org/10.1080/01944360508976405 }}$ 
Strength of provincial legislative frameworks to protect farmland

Norton, R. K. (2008). Using content analysis to evaluate local master plans and zoning codes. Land Use Policy, 25(3), 432454. https://doi.org/10.1016/j.landusepol.2007.10.006

Ontario Farmland Trust. (2021, February 9). MZOs and Farmland. Retrieved from Ontario Farmland Trust website: https://ontariofarmlandtrust.ca/2021/02/09/mzos-andfarmland/

Ontario Nature. (2021). Letter to Planning Consultation Team, Ministry of Municipal Affairs.

Pierce, J. T., \& Séguin, J. (1993). Exclusive agricultural zoning in British Columbia and Québec: Problems and prospects. In A. W. Gilg (Ed.), Progress in rural policy and planning (Vol. 3, pp. 287-310). London, UK: Belhaven Press.

Rawson, M. (1976). Ill fares the land. Land-use management at the urban/rural/resource edges: The British Columbia Land Commission. The Ministry of State for Urban Affairs.

Smith, B. (2017). The farmland preservation program in British Columbia. In W. J. Caldwell, S. Hilts, \& B. Wilton (Eds.), Farmland Preservation Land for Future Generations (pp. 6493). Winnipeg, MB: University of Manitoba Press.

Statistics Canada (2014). Human activity and the environment: Agriculture in Canada. Environment, Energy and Transportation Statistics Division. Catalogue no. 16-201-X.

Statistics Canada (2016). Human Activity and the Environment: The changing landscape of Canadian metropolitan areas. Environment, Energy and Transportation Statistics Division. Catalogue no. 16-201-X.

Stevens, M. R. (2013). Evaluating the Quality of Official Community Plans in Southern British Columbia. Journal of Planning Education and Research, 33(4), 471-490. https:// doi.org/10.1177/0739456X13505649

Tan, R., Beckmann, V., van den Berg, L., \& Qu, F. (2009). Governing farmland conversion: Comparing China with the Netherlands and Germany. Land Use Policy, 26(4), 961-974. https://doi.org/10.1016/j.landusepol.2008.11.009 


\section{APPENDIX A. FACTORS FOR RATING EACH PRINCIPLE, FOR SENIOR GOVERNMENTS}

\begin{tabular}{|c|c|c|c|c|}
\hline & Maximize stability & $\begin{array}{l}\text { Integrate across } \\
\text { jurisdictions }\end{array}$ & Minimize Uncertainty & Accommodate flexibility \\
\hline $5=$ Very strong & $\begin{array}{l}\text { Clear, direct } \\
\text { commitment to protect } \\
\text { farmland entrenched in } \\
\text { law; all agricultural } \\
\text { lands protected; } \\
\text { comprehensive } \\
\text { complement of } \\
\text { regulations, policies, and } \\
\text { guides. }\end{array}$ & $\begin{array}{l}\text { Clear, direct } \\
\text { requirements for } \\
\text { consistency; upper-level } \\
\text { approval authority }\end{array}$ & $\begin{array}{l}\text { Permitted uses clearly } \\
\text { articulated and } \\
\text { entrenched in law; senior } \\
\text {-level targets set for } \\
\text { urban growth } \\
\text { management to be } \\
\text { implemented at lower } \\
\text { levels; no loopholes, } \\
\text { vague language, or } \\
\text { qualifying statements } \\
\text { that undermine } \\
\text { commitment }\end{array}$ & $\begin{array}{l}\text { Senior level, quasi- } \\
\text { judicial governing body } \\
\text { (e.g., commission); } \\
\text { application process (or } \\
\text { equivalent); agricultural } \\
\text { impact assessment } \\
\text { process that directs } \\
\text { development to land of } \\
\text { lower agricultural } \\
\text { capability }\end{array}$ \\
\hline 4- Strong & $\begin{array}{l}\text { Clear, direct } \\
\text { commitment to protect } \\
\text { farmland entrenched in } \\
\text { law; some key } \\
\text { supporting elements, but } \\
\text { not a full complement }\end{array}$ & $\begin{array}{l}\text { One of: clear, direct } \\
\text { requirements for } \\
\text { consistency; upper-level } \\
\text { approval authority; or } \\
\text { moderate combination of } \\
\text { both. }\end{array}$ & $\begin{array}{l}\text { Some elements of 'very } \\
\text { strong' are missing }\end{array}$ & $\begin{array}{l}\text { Some elements of 'very } \\
\text { strong' are missing }\end{array}$ \\
\hline 3-Moderate & $\begin{array}{l}\text { Recognition of the } \\
\text { importance of preserving } \\
\text { farmland; may be in } \\
\text { policy statement rather } \\
\text { than law }\end{array}$ & $\begin{array}{l}\text { Some general } \\
\text { requirements, but not be } \\
\text { as clear, direct; one of } \\
\text { requirement for } \\
\text { consistency or approval } \\
\text { authority is missing }\end{array}$ & $\begin{array}{l}\text { A 'balanced' approach } \\
\text { that seeks to protect } \\
\text { agricultural land while } \\
\text { recognizing importance } \\
\text { of development } \\
\text { opportunities }\end{array}$ & $\begin{array}{l}\text { Basic recognition of } \\
\text { need to accommodate } \\
\text { non-farm development } \\
\text { while limiting impacts } \\
\text { on agricultural land; no } \\
\text { supporting mechanisms }\end{array}$ \\
\hline 2- Weak & $\begin{array}{l}\text { Minimal reference to } \\
\text { agriculture beyond } \\
\text { minimum requirements }\end{array}$ & Minimal requirements & $\begin{array}{l}\text { Some expressed interest } \\
\text { in developing } \\
\text { agricultural land; } \\
\text { significant exposure to } \\
\text { non-farm development }\end{array}$ & $\begin{array}{l}\text { Minimal attempt to } \\
\text { minimize impacts (e.g., } \\
\text { brief, general } \\
\text { statement); no } \\
\text { supporting mechanisms }\end{array}$ \\
\hline 1- Very weak & $\begin{array}{l}\text { No reference to } \\
\text { agriculture }\end{array}$ & No requirements & $\begin{array}{l}\text { Clear interest in } \\
\text { developing agricultural } \\
\text { land; fully exposed to } \\
\text { non-farm development }\end{array}$ & $\begin{array}{l}\text { No attempt to minimize } \\
\text { impacts }\end{array}$ \\
\hline
\end{tabular}




\section{APPENDIX B. WeIGHTING PROTOCOL FOR EACH PRINCIPLE}

a) Maximize stability

Original score is doubled.

\begin{tabular}{|c|c|}
\hline Original score & Weight factor \\
\hline 5 & 10 \\
\hline 4 & 8 \\
\hline 3 & 6 \\
\hline 2 & 4 \\
\hline 1 & 2 \\
\hline
\end{tabular}

b) Integrate public priorities across jurisdictions

Original scores for stability and for integration are combined. Combinations of higher scores have greater weighting than lower combinations of original score

\begin{tabular}{|l|c|c|c|c|c|c|}
\hline \multicolumn{2}{|c|}{} & \multicolumn{2}{l}{ Integration: original score } & \multicolumn{2}{l|}{} \\
\cline { 2 - 7 } \multicolumn{2}{c|}{} & 5 & 4 & 3 & 2 & 1 \\
\hline \multirow{3}{*}{$\begin{array}{l}\text { Stability: } \\
\text { original } \\
\text { score }\end{array}$} & 5 & 2.0 & 1.75 & 1.0 & 0.5 & 0.25 \\
\cline { 2 - 7 } & 4 & 1.75 & 1.5 & 1.0 & 0.5 & 0.25 \\
\cline { 2 - 7 } & 3 & 1.0 & 1.0 & 0.75 & 0.5 & 0.25 \\
\cline { 2 - 7 } & 2 & 0.5 & 0.5 & 0.5 & 0.25 & 0.25 \\
\cline { 2 - 7 } & 1 & 0.25 & 0.25 & 0.25 & 0.25 & 0.25 \\
\hline
\end{tabular}

c) Minimize uncertainty

The range of the original scale is expanded to give more/less weight to each end of the scale.

\begin{tabular}{|c|c|}
\hline Original score & Weight factor \\
\hline 5 & 7.5 \\
\hline 4 & 6 \\
\hline 3 & 3 \\
\hline 2 & 1 \\
\hline 1 & 0.5 \\
\hline
\end{tabular}

d) Accommodate flexibility

The weighting is based on the sum of the original scores for the other three principles. Lower total scores have lower weighting.

\begin{tabular}{|c|c|}
\hline $\begin{array}{c}\text { Sum of original } \\
\text { scores }\end{array}$ & Weight factor \\
\hline $11-15$ & 1 \\
\hline $5-10$ & 0.5 \\
\hline $0-4$ & 0.25 \\
\hline
\end{tabular}

e) Seven-point scale for overall strength of policy focus

\begin{tabular}{|l|l|}
\hline Rating & Range \\
\hline Very strong & $>=27.8$ \\
\hline Strong & $>=23.2$ \\
\hline Somewhat strong & $>=18.5$ \\
\hline Moderate & $>=13.0$ \\
\hline Somewhat weak & $>=9.0$ \\
\hline Weak & $>=4.6$ \\
\hline Very Weak & $<4.6$ \\
\hline
\end{tabular}

